Journal of Case Reports 2018;8(3):194-197

\title{
Peritoneal Dialysis: A Life-Saving Measure in an Infant with Single Functioning Kidney
}

\author{
Karniza Khalid $^{1}$, Koik Boon Hong ${ }^{2}$, Abdul Nasir Mohamed Abdul Kadher ${ }^{2}$ \\ ${ }^{1}$ Clinical Research Centre, Hospital Tuanku Fauziah, Perlis, Ministry of Health, Malaysia; ${ }^{2}$ Department of Pediatrics, Hospital \\ Tuanku Fauziah, Perlis, Ministry of Health, Malaysia.
}

\section{Corresponding Author:}

Dr. Karniza Khalid

Email: karniza.khalid@moh.gov.my

This is an Open Access article distributed under the terms of the Creative Commons Attribution License (creativecommons.org/ licenses/by/3.0).

Received Accepted Published

February 12, 2018 July 17,2018 August 15, 2018

\begin{abstract}
Background: Peritoneal dialysis is a clinical procedure performed to assist functions of the failing kidney. Its application in modern clinical practice is gradually curtailed by hemodialysis, a system with a robust technology. Case Report: This case describes an infant with primary urolithiasis whose parents refused for any medical evaluation until the infant came to medical attention again at seven months of age in a tertiary medical center in northern Malaysia. At that point, his left kidney was already non-functional. $\mathrm{He}$ presented with severe acute-on-chronic renal failure with profound electrolyte imbalances resulting in status epilepticus and cardiac dysrhythmia. He was contiguously planned for further diagnostic and therapeutic surgical intervention but due to his unstable condition, he was not able to be transferred to a referral center for the definitive care. Peritoneal dialysis was subsequently done in our center and delivered an excellent outcome. The patient was later safely transferred for definitive care. Conclusion: Peritoneal dialysis proves to be a cheap, safe and cost-effective method in the management of severe acute kidney injury in an infant with a single functioning kidney. Despite being a rudimentary technique, peritoneal dialysis proves beneficial in situation where pediatric surgical expertise is lacking.
\end{abstract}

Keywords: Acute Kidney Injury, Malaysia, Peritoneal Dialysis, Solitary Kidney, Urolithiasis.

\section{Introduction}

Peritoneal dialysis (PD) is an invasive procedural technique aims at recovering renal function in whom supportive therapy is not adequate to satisfy the metabolic demands [1]. Nowadays, with the advance of medical technology, the technique is only practiced in only few centers' as a result of lack of expertise, manpower, as well as equipment [2]. PD technique in pediatrics, particularly is not routinely trained as a core procedure among general pediatricians and not every general pediatrician has the skill and confidence to perform, especially in acute emergencies.

\section{Case Report}

This case describes a seven month old infant, whose mother was found to have oligohydramnios (AFI: $6 \mathrm{~cm}$ ) during her late gestational age. The repeated kidney-ureter-bladder (KUB) ultrasound at the child's six weeks of life revealed features likely to represent hydronephrosis of left kidney and ureterocoele posterior to the urinary bladder. These findings demanded further evaluation to determine the cause of his obstructive uropathy features but unfortunately, the parents refused for further testing despite repeated counselling by the managing team. The child first presented 
to our center at age of two months for urinary tract infection. He was successfully treated with empirical antibiotics for seven days. The child was planned for flexible cysto-urethrogram and an MRI abdomen to which the parents adamantly refused. The parents defaulted subsequent follow-ups and refused for further diagnostic testing.

Unfortunately, the child later presented to us again at 7-month of age with two days history of fever, vomiting and recurrent episodes of seizures. He developed status epilepticus six hours after admission and was loaded with intravenous phenytoin $20 \mathrm{mg} / \mathrm{kg}$. He was intubated and ventilated for cerebral protection. He was ill, severely dehydrated and cachexic. The parents were counselled regarding the child's grave clinical condition and death-in-line (DIL) was issued.

His first renal profile revealed severe hyponatraemia (sodium: $123 \mathrm{mmol} / \mathrm{L}$ ) and critical hyperkalaemia (potassium: $6.6 \mathrm{mmol} / \mathrm{L}$ ). His urea and creatinine readings continued to worsen reaching its highest level at $37 \mathrm{mmol} / \mathrm{L}$ and 542 $\mu \mathrm{mol} / \mathrm{L}$ respectively. His progressive acute-onchronic renal failure with profound electrolyte imbalances resulted in ventricular tachycardia with pulse and recurrent status epilepticus episodes.

A total of five cycles of lytic cocktails and a regular 6-hourly resonium were given consecutively for three days in the attempt to bring down the potassium level. His blood culture was positive with sensitive-strain Proteus mirabilis. He was treated for urosepsis and was given one week course of intravenous meropenem $290 \mathrm{mg}$ 8 hourly $(40 \mathrm{mg} / \mathrm{kg} /$ dose $)$. MRI abdomen done showed atrophied most likely non-functioning left kidney with mildly dilated left distal ureter [Fig.1] as well as compensatory right renal hypertrophy with upper third right ureteric calculi causing obstructive uropathy. His condition warranted for surgical release but unfortunately, the patient was unfit for transportation at that crucial point in time.

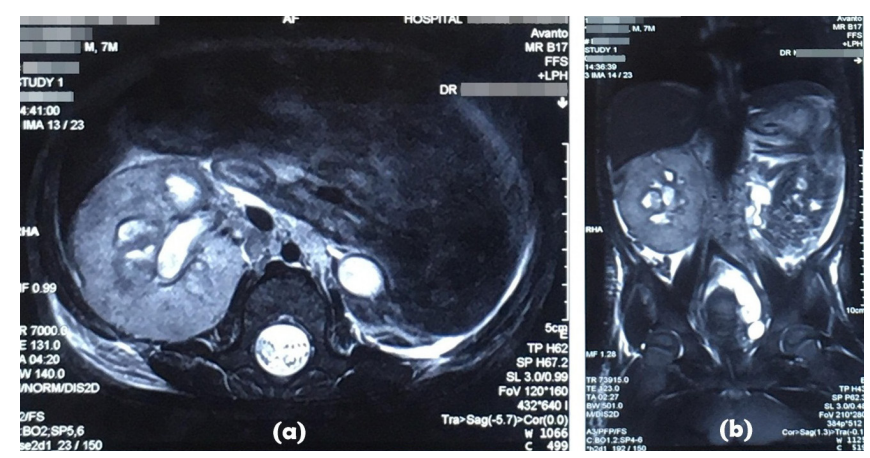

Fig.1: MRI abdomen (a) axial view (b) coronal view showing atrophied most likely non-functioning left kidney with compensatory right renal hypertrophy.

After a remote discussion with the consultant pediatric surgeon from a local tertiary center, peritoneal dialysis was done at our center as a temporary life-saving measure. Peritoneal dialysis was done under aseptic technique in pediatric intensive care unit (PICU) setting using a soft Tenckoff catheter. The dialysate concentration used was guided with a 6-hourly renal function monitoring and the strict hourly basis intakeoutput charting. His urea and creatinine level was successfully reduced to $8.8 \mathrm{mmol} / \mathrm{L}$ and 225 $\mu \mathrm{mol} / \mathrm{L}$ respectively by day four of peritoneal dialysis as tabulated [Table 1]. There was no immediate complication from the procedure. PD had successfully improved the patient's renal function parameters with normalization of electrolytes level. His seizure was controlled and his hemodynamic was stable.

Ventilator setting was gradually weaned down and he was successfully extubated to nasal prong oxygen after six days of artificial ventilation. He was successfully transferred to a tertiary center the following day where he underwent a cystoscopy and bilateral retrograde pyelogram (RPG). Intra-operative findings revealed a ruptured left ureterocele, dilated right collecting system with a filling defect seen at the distal ureter. A double-J (DJ) stenting was inserted into the right ureteric opening to release his right ureteric obstruction. 
PD was removed at the tertiary center after ten days of insertion. He was discharged well after a total of 40 days of hospitalization. He was seen again as an outpatient a week later, thriving well with a slight delay in his developmental milestones, which is attributable to his chronic illness. The parents were now committed to the medical treatment plan and agreed to play active roles as efficient caregivers.

\section{Discussion}

Pediatric urolithiasis cases are gradually rising in the recent decades $[3,4]$ with increasing metabolic abnormalities observed, such as hypo-citraturia and hyper-calciuria [5]. Anatomic anomalies may also contribute to the etiology of pediatric urolithiasis [6]. Routine blood tests were generally inconclusive hence, a 24-hour urine collection was suggested as the primary diagnostic test for pediatric urolithiasis [5,7]. Our patient manifested evidence of obstructive uropathy in his infancy, which was as early presentation as compared to the finding by Warshaw et al. which found that the mean age at the initial sign of obstructive uropathy was at 3.5 years old, amongst the 54 children with end-stage renal disease resulting from obstructive uropathy [8]. Furthermore, the study also revealed that despite early surgical management, patients inadvertently ended up progressing to end-stage renal failure, requiring regular dialysis to maintain homeostasis [8].

This case report stresses on the importance of any life-saving procedure no matter how archaic it may be. As observed in our case, peritoneal dialysis has proven to be an effective method to restore electrolyte imbalances and promote recovery especially when the primary uro-surgical expertise and resources are limited. The technical simplicity of a peritoneal dialysis, the lack of a need for anticoagulation or placement of a central venous catheter, its excellent tolerance in hemodynamically unstable patients, and the provision of adequate clearances for most
Table 1: Daily urea/creatinine trend with peritoneal dialysis in place.

\begin{tabular}{|l|l|l|}
\hline & Urea $(\mathrm{mmol} / \mathrm{L})$ & Creatinine $(\mu \mathrm{mol} / \mathrm{L})$ \\
\hline Before PD & 37.0 & 542 \\
\hline Day-1 PD & 21.0 & 345 \\
\hline Day-2 PD & 14.0 & 275 \\
\hline Day-3 PD & 11.0 & 235 \\
\hline Day-4 PD & 8.8 & 225 \\
\hline
\end{tabular}

infants have made it an excellent and cheaper alternative when compared to hemodialysis for the management of acute kidney injury in children $[1,2]$. The technique to perform peritoneal dialysis in pediatric age group is not a mandatory skill that is required for a general paediatrician. Hence, this value-added skill was customarily acquired among those who were trained in centers where an advanced pediatric hemodialysis machines were limited.

This case report briefly highlighted the issue of medical neglect, as the parents failed to provide adequate medical care when they refused for further diagnostic testing as advised by the managing pediatric team from early on. Despite medical neglect been listed under the nation's child abuse laws, the enforcement of child services was still at the minimum [9]. In the developing Asian region, parents were unsure, sceptic and more resistant to the medical technology and medicines from the West [10]. The parents assumed the ultimate authoritarian power to make the decision for their children, at times resisting treatment even for diseases known to have cure. Such scenarios have become common in regional medical practice, urging the need for an expansive public health education.

\section{Conclusion}

Peritoneal dialysis is an added skill crucial to a clinician in managing acute medical emergencies even in pediatric population, especially in vicinities afar from tertiary centres. 
Acknowledgement: The author would like to thank Director General of Health Malaysia for his permission to publish the paper.

Contributors: KK did manuscript writing, and literature search. KBH gave critical inputs into the manuscript and was managing pediatrician for the case. ANMAK did manuscript editing. KK will act as guarantor. All authors approved the final version of this manuscript.

Funding: None; Competing interests: None stated.

\section{References}

1. Félix MB. Peritoneal dialysis in the pediatric intensive care unit setting. Peritoneal Dialysis International Journal. 2009;29:S183-185.

2. Obiagwu PN. Peritoneal dialysis vs. haemodialysis in the management of paediatric acute kidney injury in Kano, Nigeria: a cost analysis. Tropical Medicine and International Health Journal. 2015;20:2-7.

3. Wang HHS, Wiener JS, Lipkin ME, Scales CD Jr, Ross SS, Routh JC. Estimating the nationwide, hospital based economic impact of pediatric urolithiasis. J Urol. 2015;193:1855-1859.

4. Kusumi K, Becknell B, Schwaderer A. Trends in pediatric urolithiasis: patient characteristics, associated diagnoses, and financial burden. Pediatr Nephrol. 2015;30:805-810.

5. VanDervoort K, Wiesen J, Frank R, Vento S, Crosby $\mathrm{V}$, Chandra $\mathrm{M}$, et al. Urolithiasis in pediatric patients: A single center study of incidence, clinical presentation and outcome. J Urol. 2007;177:2300-2305.

6. Özokutan BH, Küçükaydin M, Gündüz Z, Kabaklioglu M, Okur H, Turan C Urolithiasis in childhood. Pediatr Surg Int. 2000;16:60-63.

7. Bandari J, Dangle PP, Lyon TD, et al. 24-Hour urinary parameters in overweight and obese children with urolithiasis. J Urol. 2016;196:526-530.

8. Warshaw BL, Edelbrock H, Ettenger R, et al. Progression to end-stage renal disease in children with obstructive uropathy. J Pediatrics. 1982;100:183-187.

9. Malaysia, C.R.C. (2012). Status report on children's rights in Malaysia. Kuala Lumpur: Child Rights Coalition Malaysia. Accessed from: http://www. unicef. org/eapro/Report_on_Childrens_Rights_.pdf. Accessed on February 12, 2018.

10. Hon KLE, Leung TF, Yau HC, Chan T. Paradoxical use of oral and topical steroids in steroid-phobic patients resorting to traditional Chinese medicines. World J Pediatr. 2012;8:263-267. 